\title{
IDŐJÁRÁS
}

Quarterly Journal of the Hungarian Meteorological Service

Vol. 124, No. 3, July-September, 2020, pp. 311-330

\section{Parameter estimation and threshold selection uncertainty in extreme wind speed distribution - A frequentist approach with generalized Pareto distribution using automatic threshold selection}

\author{
Ágnes Kenéz * and Attila László Joó \\ Department of Structural Engineering \\ Budapest University of Technology and Economics \\ Müegyetem rkp. 3-9, H-1111Budapest, Hungary \\ *Corresponding author E-mail: kenez.agnes@epito.bme.hu
}

(Manuscript received in final form August 13, 2019)

\begin{abstract}
Nowadays, the use of probabilistic modeling for the design of engineering structures is becoming more and more widespread due to the advances in computer technology. In order to have a comprehensive picture about a meteorological phenomenon, e.g., wind actions on structures, uncertainties must be taken into account. From structural engineering and practical points of view, the effect of the length of short time series available for the analysis on the final results can be interesting to define a minimum observation-length. In this way, the real condition at the site can be utilized to assess wind loading effects on the structure.

This paper deals with the effect of uncertainties associated with the parameter estimation and threshold selection. A four-year record of wind speed data of Sződliget is analyzed, and these results are compared with the results of neighboring sites, Penc, and Budapest. The peak over threshold (POT) method with maximum likelihood estimation are selected to obtain the basic wind velocity. The suitable threshold is chosen using an automatic threshold selection approach.

According to our results, the applied automated threshold selection method provide reliable results, and it is simple and computationally inexpensive. This method may reduce associate errors of threshold selection in the future. It was found that at least approximately 100 realizations should exceed the specified threshold to earn reliable results. It means that $1-1.5$-year and 4-year records of wind speeds are necessary for statistical inference in case of weakly dependent observations and for statistically independent events, respectively.
\end{abstract}

Key-words: extreme wind speed, basic wind velocity, generalized Pareto distribution, automated threshold selection, parameter estimation uncertainty 


\section{Introduction}

Most design codes are based on the semi-probabilistic partial factor method, where design values should be conservative estimates. However, the advances in computer technology suggests the introduction of alternative design procedures based on fully probabilistic approaches and simulation techniques. This has led to the development of a promising design methodology, the Performance-based Wind Engineering (PBWE). The PBWE was first published in 2004 (Paulotto et al., 2004), that paper provides a general framework for these investigations. After that, the major parameters and uncertainties were summarized in Ciampoli et al. (2011), Petrini and Ciampoli (2012), and Tessari et al. (2017). These publications help to understand of many aspects of structural behavior and its modeling. A cell tower equipped with wind speed (and strain) sensors in Szödliget (Central Hungary) is selected as the subject of this research, which is used as a radio tower. According to the experience of expert engineers and our observations, the utilization of the structure can be even smaller with precise modeling of wind load, thus, more antenna can be placed on the structure. The aim of the present study is to determine the point estimate and the parameter estimation uncertainty in the environmental field in case of Hungarian climate.

A lattice tower can be used as an electricity transmission tower (especially for voltages above 100 kilovolts), as a radio tower (a self-radiating tower or as a carrier for aerials), or as an observation tower. As reported in Ducloux and Figueroa (2016), the structural behavior and response of a tangent suspension tower and a radio tower are quite different. Furthermore, major international wind codes and standards were compared in previous studies to identify the differences and similarities between them Kwon and Kareem (2013), Lungu et al. (1996), and Gatey and Miller (2007). One of the main conclusions is that alongwind responses are fairly consistent in the codes/standards, but there are discrepancies in acrosswind responses. Moreover, most of these codes use the global method, i.e., the solidity ratio and global shielding factors. Although this approach is very effective for conventional structures, it is difficult to apply for atypical configurations. As recommended by Prud'homme et al. (2018), an empirical local method could be used to determine the wind loads in such a case. Their approach is based on the reduction of wind velocity in a turbulent wake accounting the shielding effect on each member.

Future extreme wind speeds should be considered in a reliable design. The available techniques to determine the 50-year return period wind speed was reviewed and summarized in Palutikof et al. (1999) and Cooley (2016). In this paper, the measured data of a 50-meter-high steel structure antenna tower equipped with wind speed sensors is analyzed and compared to the data provided by the Hungarian Meteorological Service (OMSZ). The fundamental value of the basic wind velocity defined at $10 \mathrm{~m}$ above ground of terrain category II (EN 1991-1-4 (2010) and EN 1990 (2002)) is determined. 


\section{Measured data}

The data from the abovementioned antenna tower was provided by Hungarian Telekom Telecommunications Plc.. The wind speed was measured for the period between August 2011 and March 2015, with a sampling interval of $0.9 \mathrm{~s}$ at $25 \mathrm{~m}$, and $50 \mathrm{~m}$ height above ground. The lattice tower

is located in Szödliget, and the nearest meteorological station is in Penc. To identify terrain categories, the map is shown in Fig. 1. Terrain category III are chosen for both sites. The following data from Penc and Budapest were provided by the OMSZ:

- 1999-2017 annual maxima of 10 minutes mean wind velocity,

- 2012-2017 daily maxima of 10 minutes mean wind velocity,

- 1998-2017 annual maxima of wind gusts.

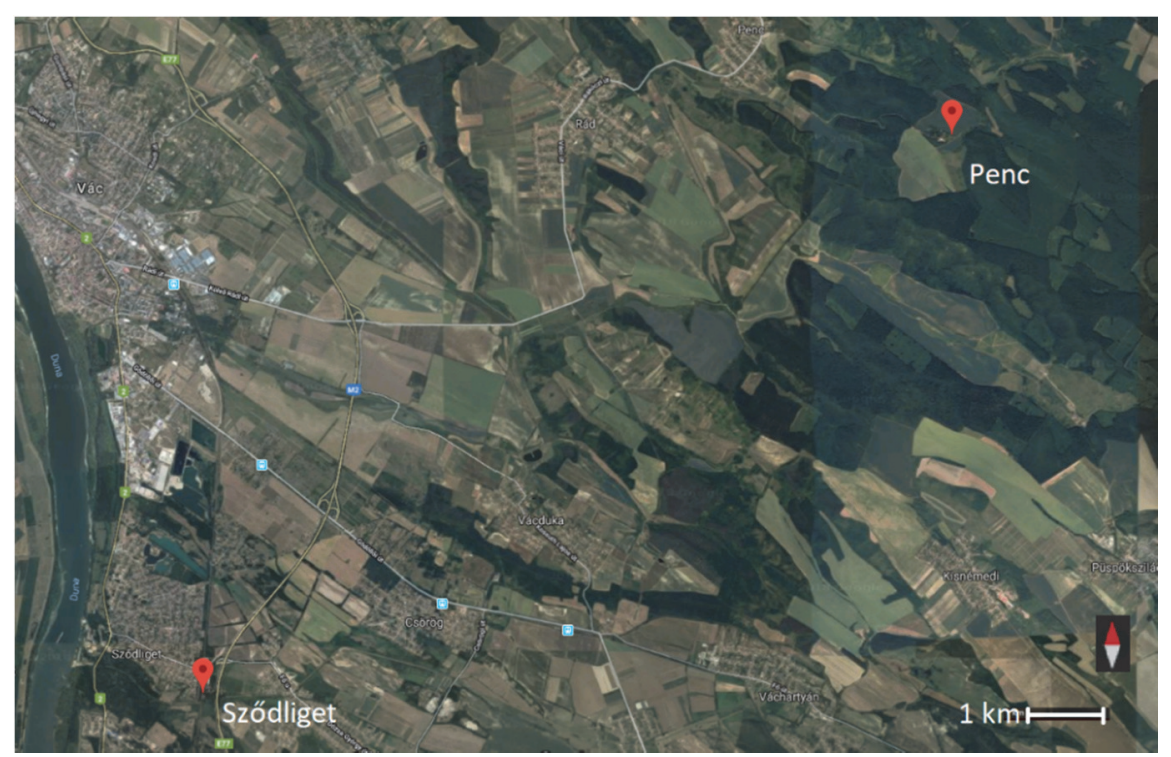

Fig. 1. Map and terrain category of Sződliget and Penc.

The time series records of maxima for 3 and 7 days are shown in Figs. 2 and 3. 


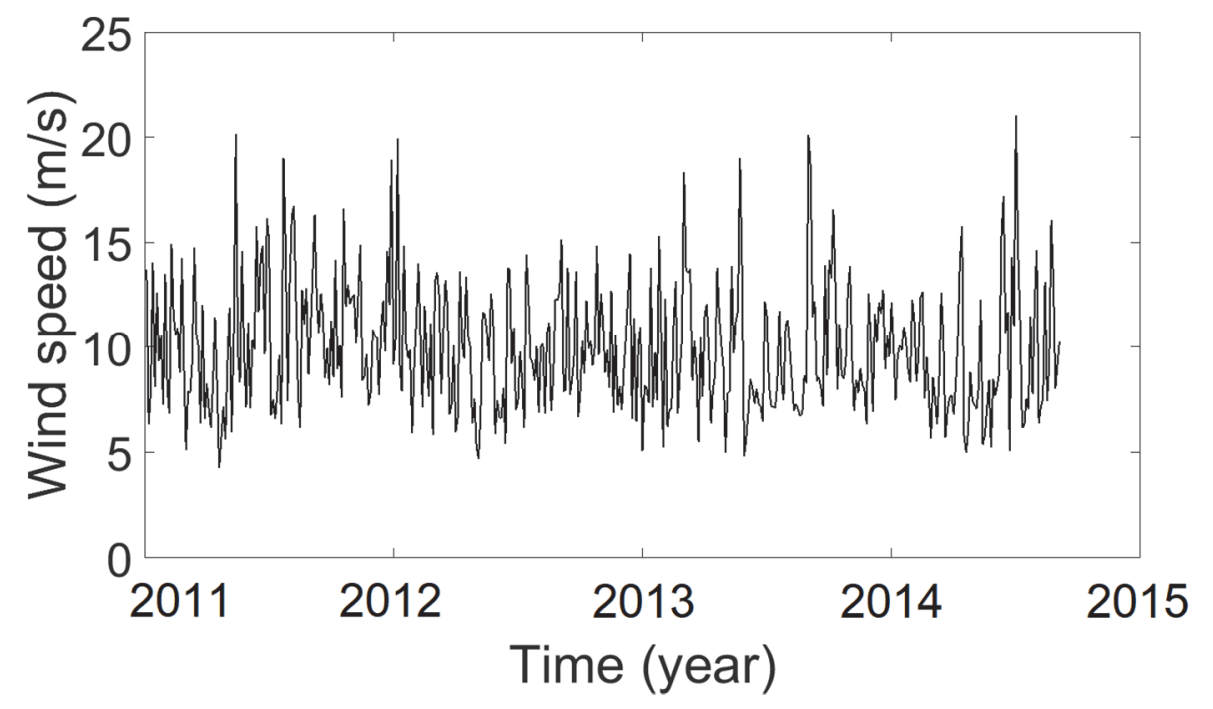

Fig. 2. Time series plot of 3-day maxima of wind speed measured at Sződliget.

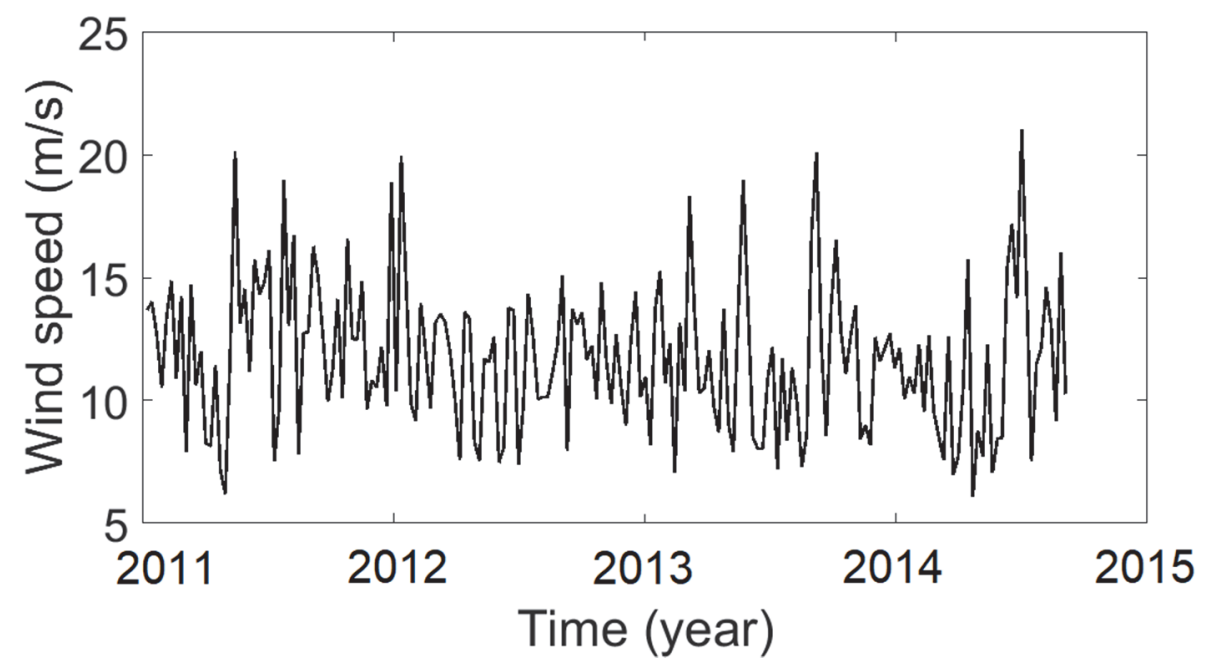

Fig. 3. Time series plot of 7-day maxima of wind speed measured at Sződliget.

\section{Applied methods}

\subsection{Independent events}

First, an autocorrelation analysis is adopted to obtain the dependencies among the data and determine statistically independent events. A previous paper (Liu et al., 2016) deals with repeating patterns and wind characteristics. Since an obvious daily periodicity of the change rate was recognized, the maxima for 3 and 7 days are analyzed in this study. This selection results in 441 and 189 data, respectively. 
In case of the 3-day maxima, the presence of a slight periodicity was identified in the autocorrelation function of the stochastic time series (Fig. 4). However, the autocorrelation function of maxima for 7 days verifies the statistically independences of events clearly (Fig. 5). The detailed results for the 7-day maxima are presented in Section 4.

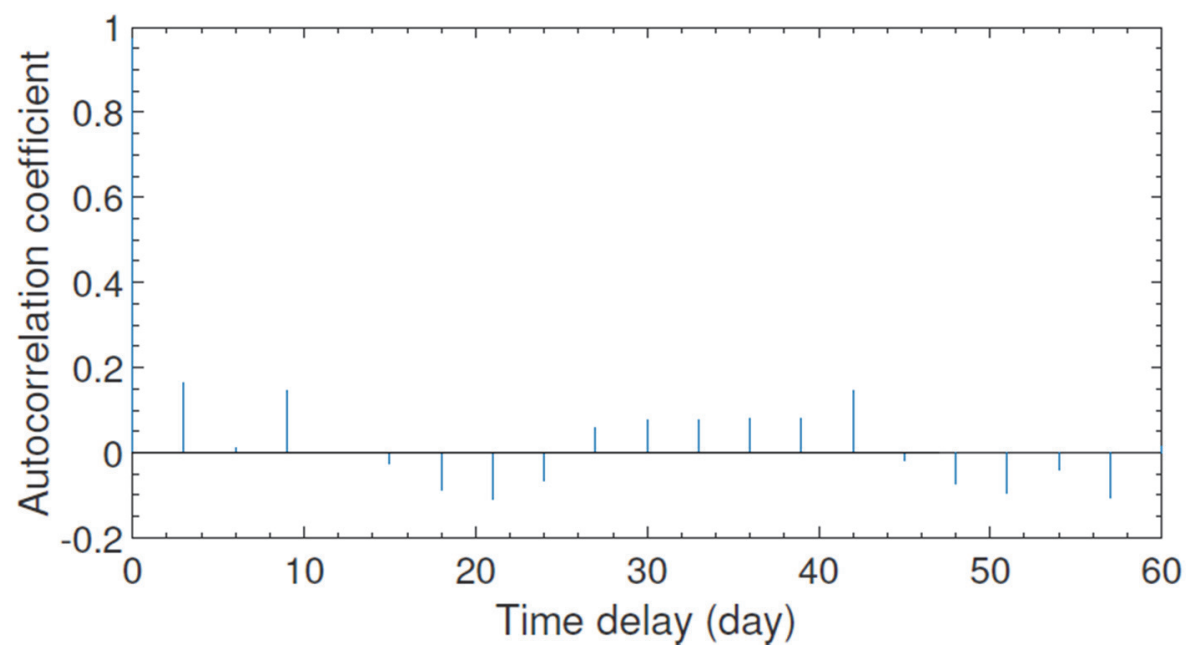

Fig. 4. Autocorrelation function of maxima for 3 days.

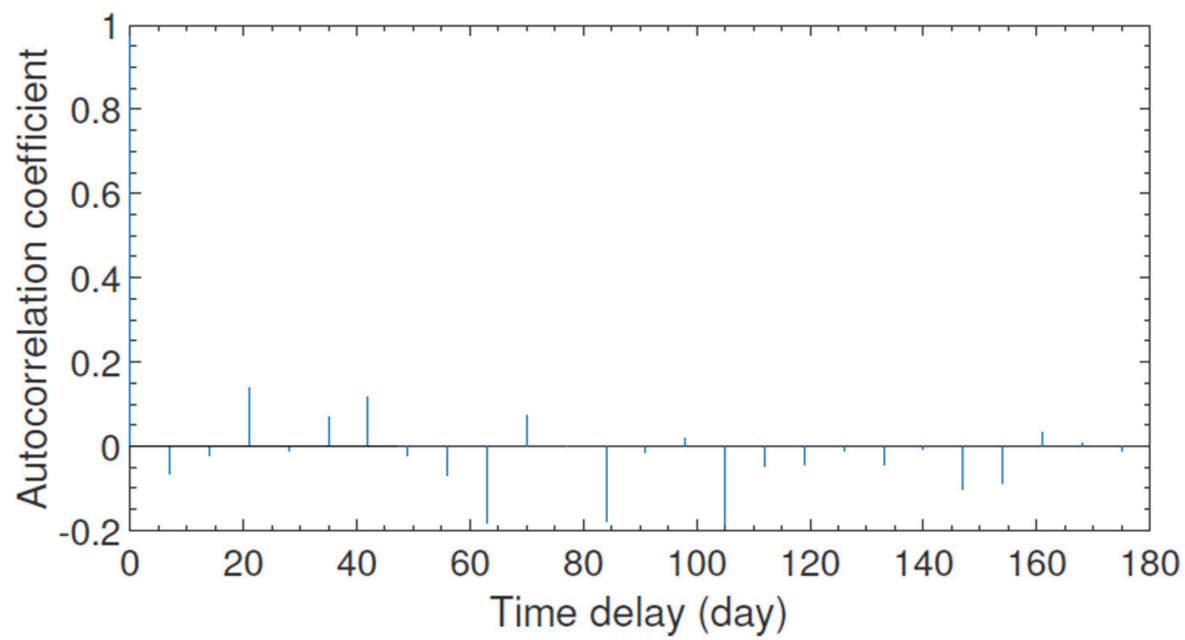

Fig. 5. Autocorrelation function of maxima for 7 days.

\subsection{Extreme value theory}

According to the classical extreme value theory (Fisher and Tippett, 1928; Gnedenko, 1943), the distribution of extreme wind speeds has an asymptotic limit. Moreover, the only possible limit $\mathrm{F}$ is the generalized extreme value distribution $(\mathrm{GEV})$, which has the following cumulative distribution function (CDF): 


$$
F_{\xi, \sigma, \eta}(x)=\left\{\begin{array}{l}
\exp \left(-\left(1+\frac{\xi(x-\eta)}{\sigma}\right)^{-\frac{1}{\xi}}\right) \text { for } \xi \neq 0 \\
\exp \left(-\exp \left(-\frac{(x-\eta)}{\sigma}\right)\right) \text { for } \xi=0
\end{array}\right.
$$

where $\xi, \sigma$, and $\eta$ are the shape, scale, and location parameters, respectively. The shape parameter determines the type of the distribution. The three distributions are Gumbel $(\xi=0)$, Fréchet $(\xi>0)$, and Weibull $(\xi<0)$, also known as type I, II, and III extreme value distributions. The Fréchet distribution has a lower limit and the Gumbel distribution is unlimited which results unlimited values as the return period increases. Thus, the Weibull distribution can be more appropriate to model extreme wind speeds for geophysical reasons (Holmes and Moriarty, 1999, 2001; Cook and Harris, 2001). The fundamental value of the basic wind velocity of Hungary has been determined using Gumbel distribution. However, the Joint Committee on Structural Safety recommends Weibull distribution in the Probabilistic Model Code.

A traditional approach of applying classical extreme value theory is the method of annual maxima. A major drawback of this approach is the data reduction, therefore, the wind measurement must be long. Cook (1985) advises that at least 20 extremes should be used to determine reliable results. To improve the efficiency, three main techniques have been developed: block method, peaksover threshold (POT) method, and method of independent storms (MIS). In this study, we focus on the POT method, which is based on a conditional distribution, i.e., the exceedances over a specified threshold. The generalized Pareto distribution (GPD) is the asymptotic distribution to model the tails of the generalized extreme value (GEV) distribution under certain condition (Pickands III, 1975). Several papers deal with the application of GPD to extreme value analysis (Holmes and Moriarty, 1999, 2001; Cook and Harris, 2001). The CDF of the GPD is

$$
F_{\xi, \sigma, \eta}(x)= \begin{cases}1-\left(1+\frac{\xi(x-\eta)}{\sigma}\right)^{-\frac{1}{\xi}} & \text { for } \xi \neq 0 \\ 1-e^{-z} & \text { for } \xi=0\end{cases}
$$

where $\xi$, $\sigma$, and $\eta$ are the shape, scale, and location parameters, respectively. The shape parameter $\xi$ of the GPD is the same as for the GEV (Pickands III, 1975). The threshold selection has a great influence on the result, and it is a compromise between bias and variance. While the variance decreases and the bias increases with lower threshold, higher threshold results that the bias decreases and the variance increases. The performance of threshold selection on visual basis is widely used, e.g., mean excess plot (or mean residual life plot; by plotting the mean of the excesses over the selected threshold against the wind velocity) which may cause associate errors. 


\subsection{Automatic threshold selection method for GPD}

An automatic threshold selection method was proposed in (Thompson et al., 2009), which was implemented in this study. This automated technique is simple and computationally inexpensive. They recommend that the suitable values of thresholds $\left(u_{j}, j=1 \ldots, n\right)$ should be chosen between the median and the $98 \%$ quantile of the data (unless fewer than 100 values exceed it). Let us define

$$
\tau_{u_{j}}=\hat{\sigma}_{u_{j}}-\hat{\xi}_{u_{j}} u_{j}, \quad j=1, \ldots, n,
$$

where the differences

$$
\tau_{u_{j}}-\tau_{u_{j-1},} \quad j=2, \ldots, n,
$$

should approximately follows normal distribution with zero mean.

\subsection{Wind velocity profile}

Finally, since available wind time series are measured at different heights, a conversion is required. The logarithmic law is utilized for wind velocity profile to calculate the basic wind velocity at $10 \mathrm{~m}$ height:

$$
V(z)=\frac{u^{*}}{0.4} \ln \left(\frac{z}{z_{0}}\right) V_{0}
$$

where $u^{*}$ is the friction velocity, $z$ is the height of interest, and $z_{0}$ is the roughness length.

\section{Results and discussion}

\subsection{Traditional graphical diagnostics}

The decreasing behavior of the mean excess plot (Fig. 6) indicates lighter tail (shape parameter $\xi<0$ ). The conditional distribution is in the domain of attraction of GPD if the mean excess plot follows a straight line. Hence, one should select the proper threshold beyond the graph appears to be linear. In this case, linearity occurs between 7 and 12. The dotted lines indicate the upper and lower 95\% confidence intervals. 


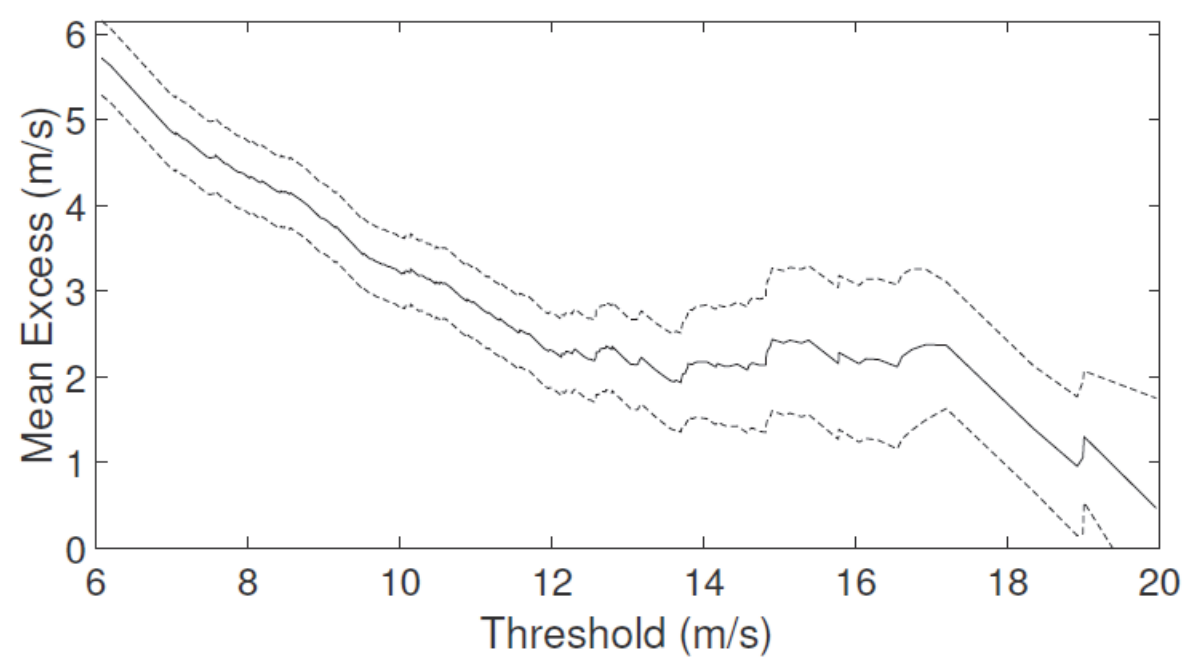

Fig. 6. Mean excess plot of the maxima for 7 days and the associated $95 \%$ confidence envelope.

Six estimation methods were considered and compared in Kang and Song (2017). Two methods are based on the maximum likelihood estimation (MLE), three methods are based on the nonlinear least squares (NLS), and the last one is the Hill estimator. They found that the MLE performs well and better than the others in most cases. However, the MLE only hold when $\xi>-0.5$ (Cooley, 2016). Therefore, the estimated parameters were calculated using MLE.

Furthermore, the suitable threshold can be selected with the help of shape and scale parameter plots presented in Figs. 7 and 8. One should find the point where the shape parameter is constant (approx. 11-13) and the scale parameter is linear (about 7-13).

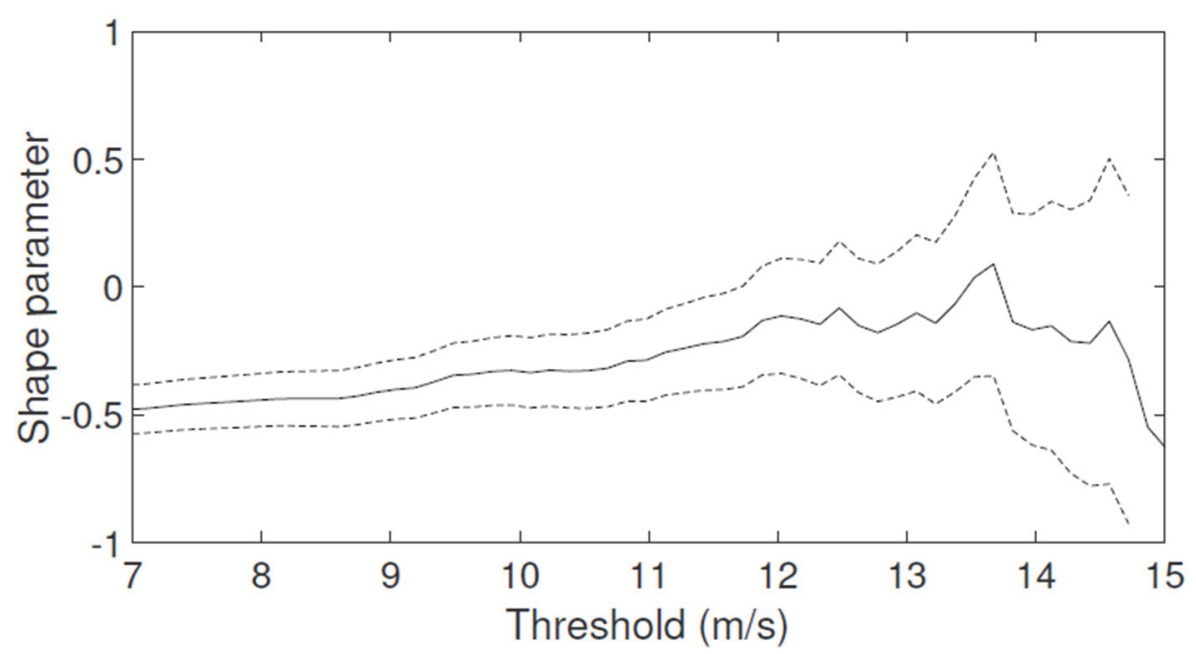

Fig. 7: Shape parameter for 7-day maxima. 


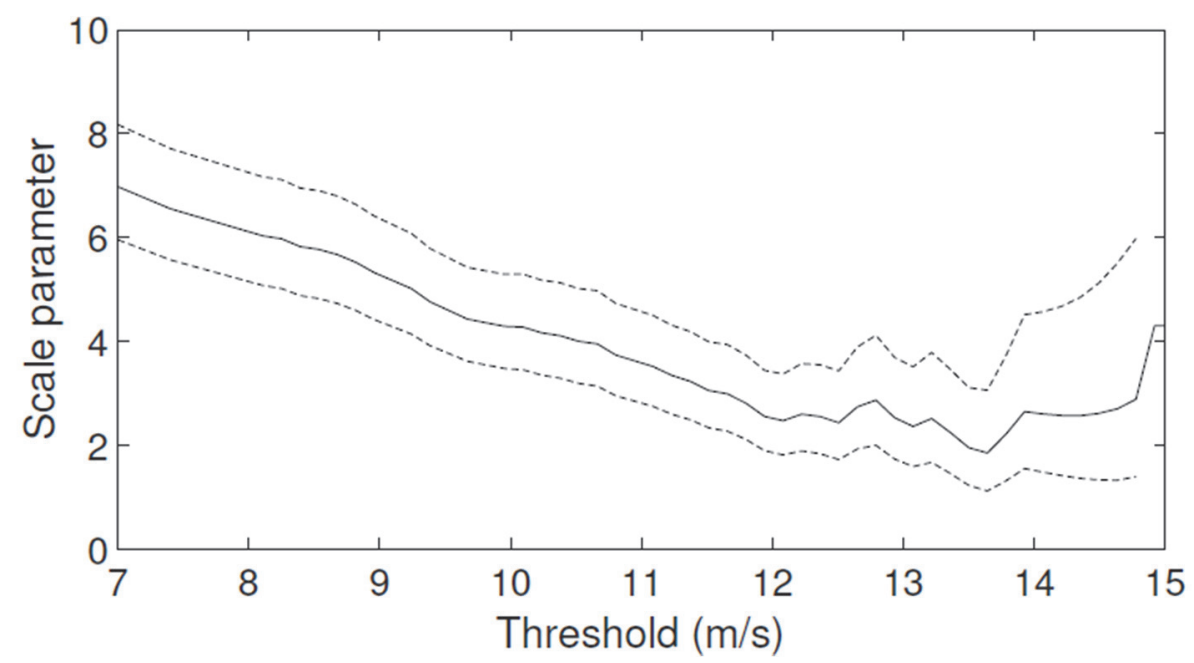

Fig. 8: Scale parameter for 7-day maxima.

\subsection{Automatic threshold selection for GPD}

The differences $\tau_{\mathrm{uj}}-\tau_{\mathrm{uj}-1}$ are calculated (Fig. 9) and the Pearson's chi-square test is used to establish whether or not the observed differences follow a normal distribution with zero mean. The red vertical line indicates the automated threshold selection choice of $11.73 \mathrm{~m} / \mathrm{s}$.

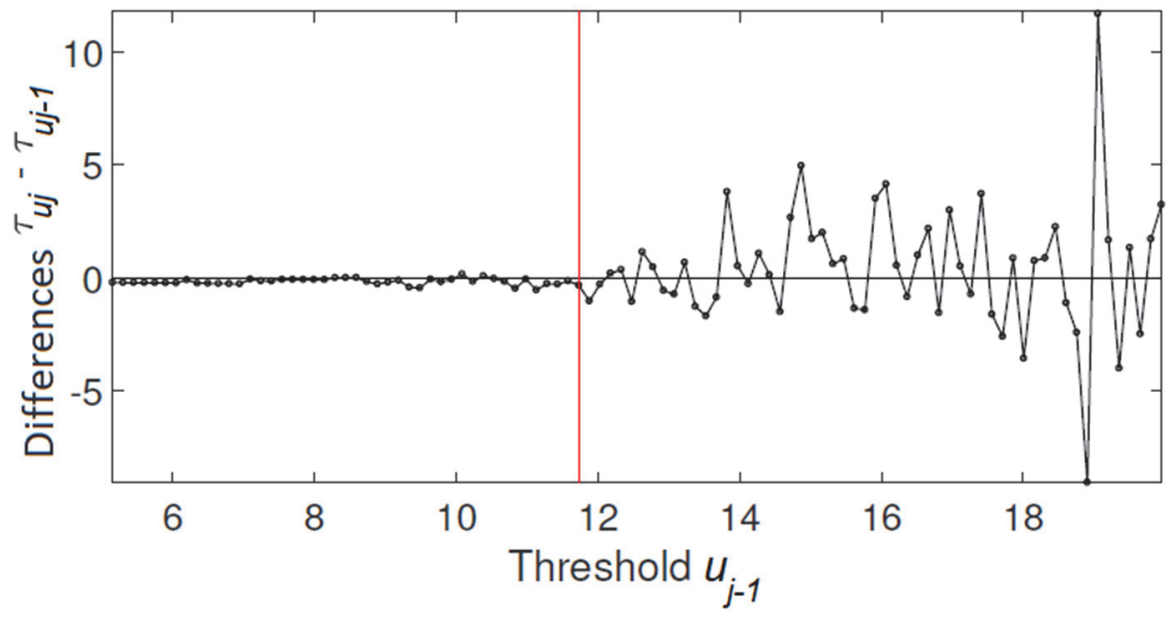

Fig. 9. Graph of the differences $\tau_{u j}-\tau_{u j-1}$ for 7-day maxima.

Fig. 10 shows the empirical and fitted cumulative distribution functions. Although the case of $\xi<0$ (belongs to Weibull distribution) would be more 
appropriate, the case of $\xi=0$ (Gumbel distribution) can be considered to be on the safe side (results greater basic wind velocity).

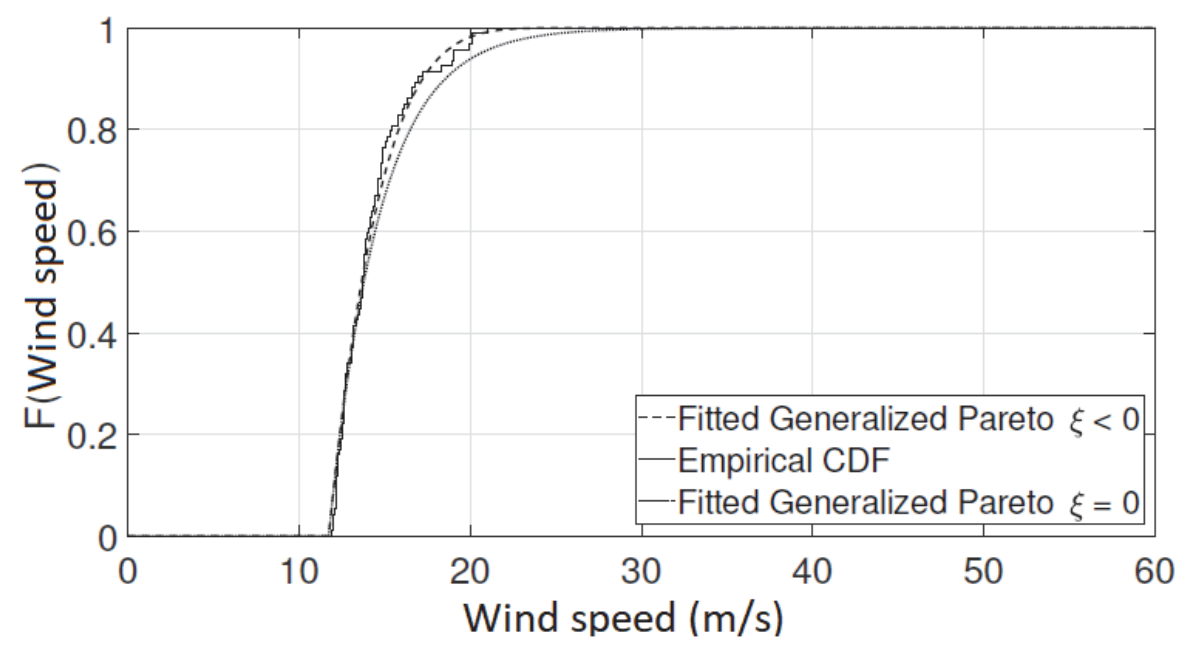

Fig. 10. Empirical and fitted cumulative distribution functions.

The quantile plot (Fig. 11) shows the quantiles of resampled estimates versus theoretical quantiles from a normal distribution. Hence, one can check that the estimated parameter follows the normal distribution, and the delta method (Coles, 2011) can be applied. This quantile plot indicates that the fitted GPD model is satisfactory.
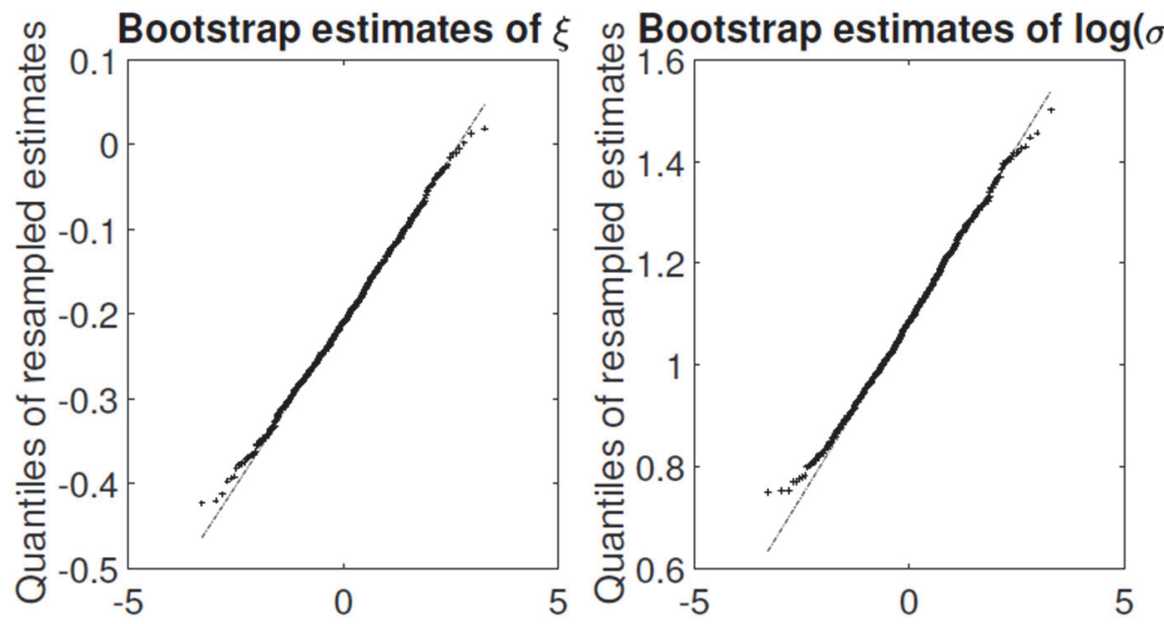

Standard Normal Quantiles

Standard Normal Quantiles

Fig. 11. Quantile plot. 


\subsection{Wind return level plot}

After the parameter estimates were determined, the wind speed for a return period is calculated from the GPD as

$$
V_{R}=\left\{\begin{array}{l}
\mu+\frac{\sigma}{\xi}\left[\left(\frac{1}{R}\right)^{-\xi}\right] \text { for } \xi \neq 0 \\
\mu-\sigma \ln \left(\frac{1}{R}\right) \text { for } \xi=0,
\end{array}\right.
$$

where $R$ is the return period. In this research, 95\% confidence intervals were calculated using the delta method. The wind return period is obtained with the estimated shape parameter (Fig. 12) and zero shape parameter Fig. 13 as well, and it is plotted with a logarithmic scale for the horizontal axis. In these plots, the bounded and unbounded behavior of the two distributions can be clearly seen.

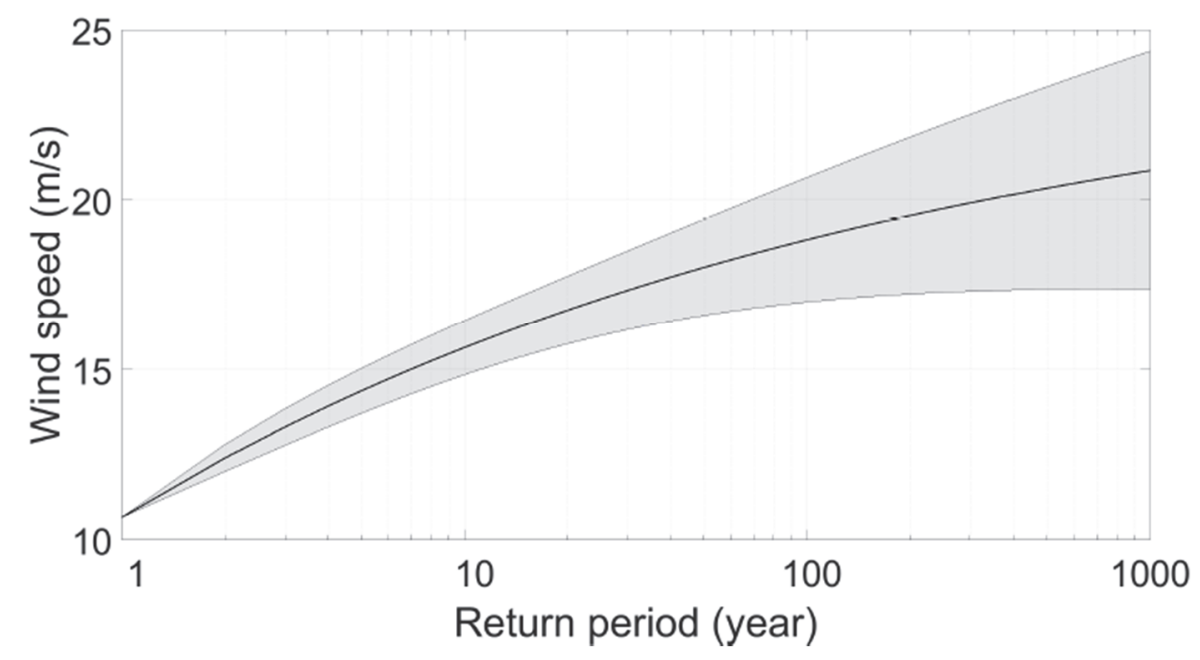

Fig. 12: Wind return plot, $\xi<0$.

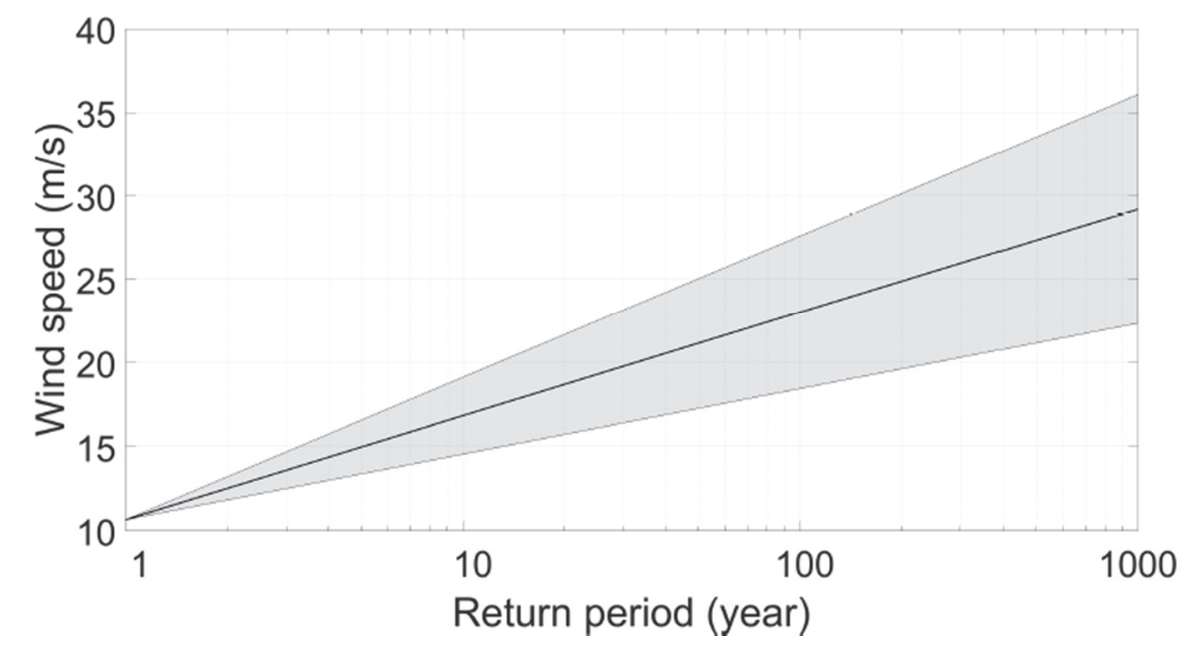

Fig. 13: Wind return plot, $\xi=0$. 
The $\xi=0$ shape parameter yields $17 \%$ greater basic wind velocity than the estimation of $\xi<0$. The range of $95 \%$ confidence intervals of the 50 -year return period wind velocities are about $7 \%$ and $13 \%$ of the associated point estimate for 3- and 7-day maxima, respectively. Certainly, this value is increasing with increasing return periods.

\subsection{4 Basic wind velocity and parameter estimation uncertainties}

The maximum likelihood estimations and the $95 \%$ confidence intervals of the 50-year return period for 3- and 7-day maxima of $10 \mathrm{~min}$ mean wind speed measured at $10 \mathrm{~m}$ height are shown in Fig. 14. The detailed results (e.g., number of observations) can be found in Appendix A, Tables A.1 to A.5. The automated threshold selection choices are $11.93 \mathrm{~m} / \mathrm{s}$ and $11.73 \mathrm{~m} / \mathrm{s}$ for 3 - and 7-day maxima, respectively.

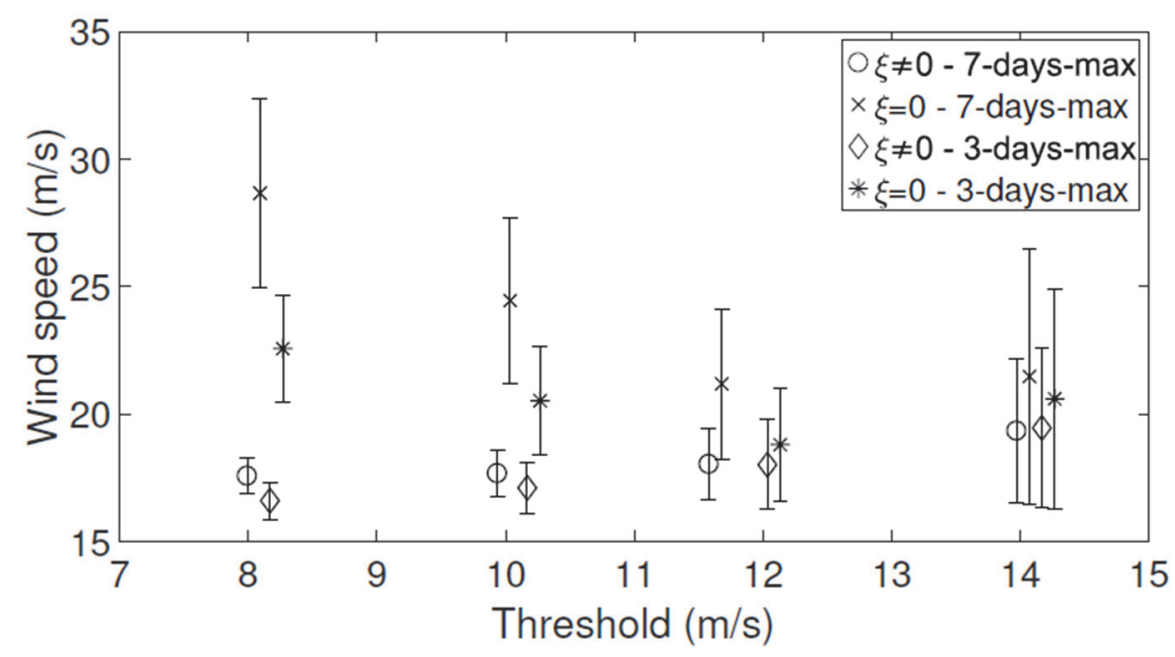

Fig. 14: Point estimates and confidence intervals of wind extremes for Sződliget.

While the point estimate calculated by shape parameter $\xi=0$ decreases with increasing threshold, maximum likelihood estimations calculated by shape parameter $\xi<0$ increases with increasing threshold due to the decreasing shape parameter. Moreover, the increasing confidence interval can be clearly seen.

Nevertheless, in case of threshold of $8 \mathrm{~m} / \mathrm{s}$ for 7-day maxima, bias was observed in the quantile plot. Reliable results are obtained in the range of $8.5 \mathrm{~m} / \mathrm{s}$ and $12.5 \mathrm{~m} / \mathrm{s}$ for 3 -day maxima, $10.5 \mathrm{~m} / \mathrm{s}$ and $13 \mathrm{~m} / \mathrm{s}$ for 7-day maxima. Although there are only small differences $(\max 5 \%)$ between estimations with shape parameter $\xi<0$ of the 3- and 7-day maxima, the differences of these estimates with shape parameter $\xi=0$ are statistically significant (4-25\%). The range of $95 \%$ confidence intervals are about $7-10 \%$ of the associated point estimates. 
Furthermore, instantaneous wind speeds are analyzed to make simple comparison between the two cases (Fig. 15). It is transformed to the basic wind velocity (10 min mean) by the exposure factor provided by Eurocode 1991-1-4 (EN 1991, 2010). Similar consequences can be stated for these results, and the two calculations are in good agreement. The estimated basic wind velocity calculated from 10 min mean wind data and instantaneous wind speeds are 18.0 $21.1 \mathrm{~m} / \mathrm{s}$ and $17.2-21.7 \mathrm{~m} / \mathrm{s}$, respectively. The automated threshold selection choices are $15.37 \mathrm{~m} / \mathrm{s}$ and $17.75 \mathrm{~m} / \mathrm{s}$ for 3 - and 7-day maxima.

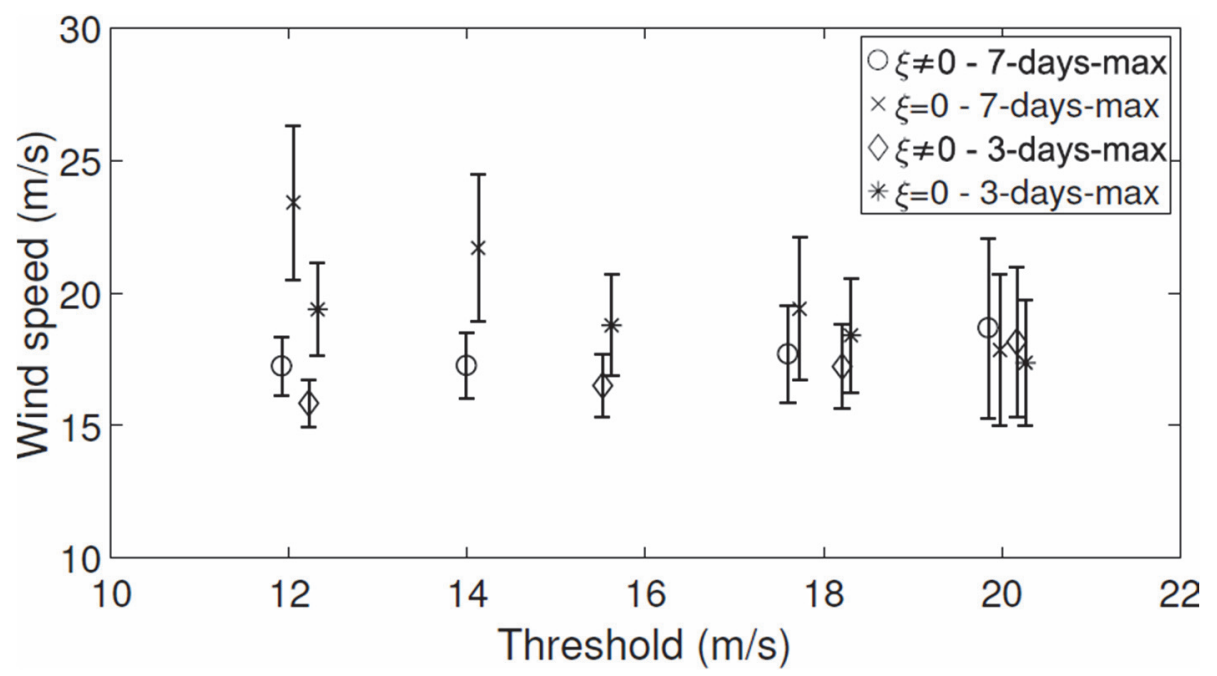

Fig. 15: Point estimates and confidence intervals of wind extremes for Sződliget (1s measured values are converted to 10 min mean).

In case of Penc, wind speeds with estimated 50-year return period are much lower than the estimates for Sződliget (about 30\%). Moreover, these values $(12-16 \mathrm{~m} / \mathrm{s})$ are also substantially lower than the basic wind velocity of Hungary $(23.6 \mathrm{~m} / \mathrm{s})$. The automated threshold selections are $5.42 \mathrm{~m} / \mathrm{s} 7.16 \mathrm{~m} / \mathrm{s}$ for $3-$ and 7 -day maxima, respectively. For Penc, the range of $95 \%$ confidence intervals are about $4-5 \%$ of the associated point estimates due to the higher number of observations and lower estimated values (Fig. 16).

The assessed basic wind speed of Budapest is in good agreement with results of Szödliget. The automated choices are $11.22 \mathrm{~m} / \mathrm{s}$ and $10.93 \mathrm{~m} / \mathrm{s}$ for 3- and 7-day maxima, respectively. The range of $95 \%$ confidence intervals of these 50 -year return period wind velocities are about $5 \%$ and $14 \%$ of the associated point estimate for 3- and 7-day maxima, respectively. The $\xi=0$ shape parameter yields approximately $20 \%$ greater basic wind velocity than the estimation of $\xi<0$. The result of the 3-and 7-day maxima data are quite equivalent for $\xi<0$. A previous study (Rózsás and Sýkora, 2016) investigated the probabilistic modeling of basic wind speeds for Budapest based on Carpatclim data covering a 50-year observation period. Although, the point estimates of $20.9-21.4 \mathrm{~m} / \mathrm{s}$ are obtained 
using the POT method, the uncertainty interval is narrower due to the greater sample size (3-4 times more observations).

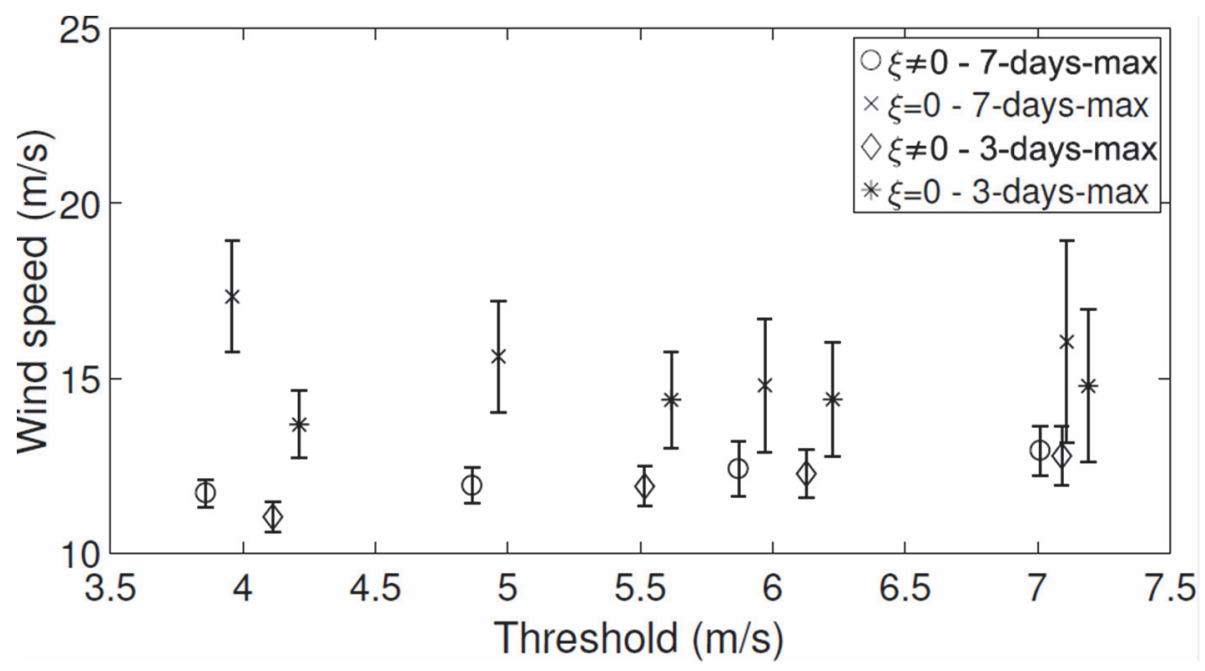

Fig. 16. Point estimates and confidence intervals of wind extremes for Penc.

Moreover, 20 years of annual maxima are analyzed using the classical GEV method for Penc and Budapest as it was suggested in Cook (1985). However, discrepancies were found in these results. Basic wind velocities calculated from 10 min mean annual maxima (see Table A.3) are slightly greater (differences are $12-15 \%$, about $2 \mathrm{~m} / \mathrm{s}$ ) than results calculated using the POT method, but still lower than the basic wind velocity of Hungary. Nevertheless, wind extremes calculated from instantaneous wind speeds are much greater (differences are $30-94 \%$ ) and these values are also greater than the fundamental basic wind velocity of Hungary.

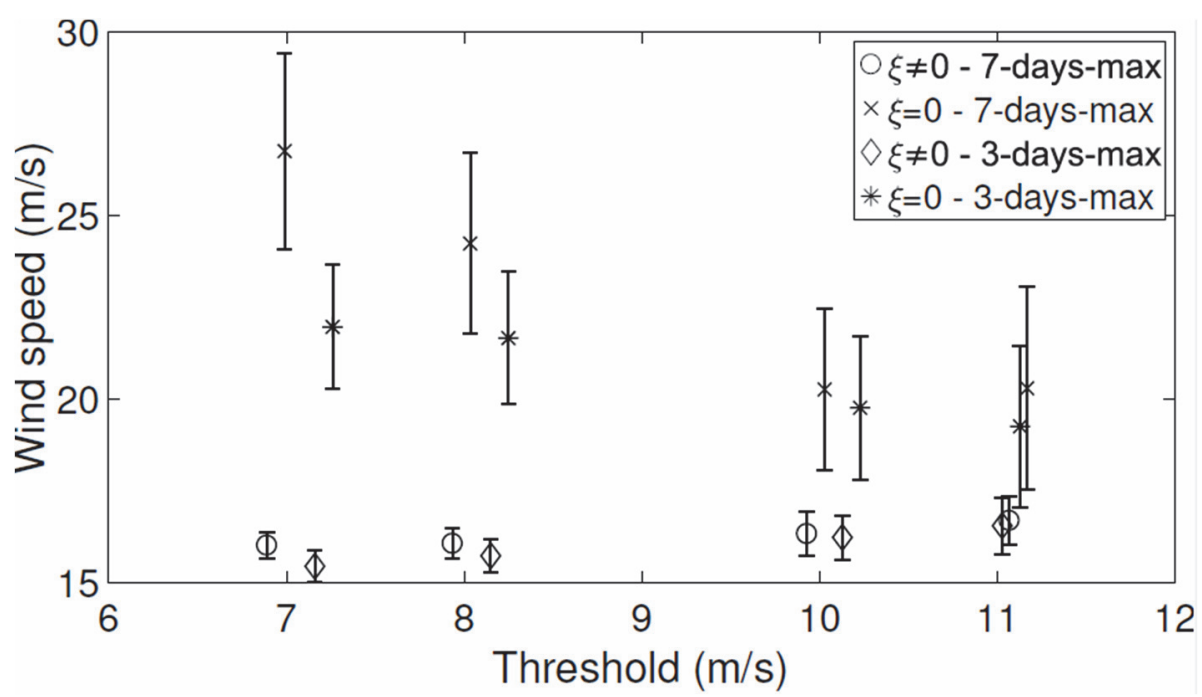

Fig. 17: Point estimates and confidence intervals of wind extremes for Budapest 


\section{Concluding remarks}

Eurocodes are based on the limit state concept used in conjunction with a partial factor method, where the basic variables (i.e., actions, resistances and geometrical properties) are given through the use of partial factors and design values (1990, 2002). If one would like to apply alternative design procedures based on fully probabilistic approaches, uncertainties must be taken into account. From structural engineering point of view, the effect of the length of short time series available for the analysis can be interesting to define a minimum observationlength, i.e., minimum number of realizations or exceedances.

In this study, uncertainties associated with the parameter estimation of the 50 -year return period wind velocity was assessed using frequentist statistical approach. This uncertainty is quantified by $95 \%$ confidence intervals. The peak over threshold (POT) method with maximum likelihood estimation are applied to analyze a four-year record of wind speed data. The threshold selection may have a great influence on the result, and it is a compromise between bias and variance. In this paper, the suitable threshold for the POT method is chosen using an automatic threshold selection approach. The following statements are valid for the dataset under consideration, since different climatic conditions can cause different behavior.

The applied automated threshold selection method provides reliable results in our case. All automated threshold choices are in the linear range in the mean excess plot, i.e., in the domain of attraction of the GPD. This automated method is simple and computationally inexpensive, and it may be able to reduce associate errors of threshold selection in the future. It was found that at least 100 realizations should exceed the specified threshold to earn reliable results. It means that 1-1.5year and 4-year records of wind speeds are necessary in case of weakly dependent observations and for statistically independent events, respectively. The range of $95 \%$ confidence intervals are about $7-10 \%$ of the associated point estimates in case of about 100 exceedances. This confidence intervals reduce to $3-5 \%$ when the number of exceedances increases by $2-3$-times.

The GPD with shape parameter $\xi=0$ yields about $10-20 \%$ greater 50 -return period wind speeds than with $\xi<0$. The former one is unbounded and conservative. The difference between point estimates calculated using the shape parameter $\xi<0$ with various thresholds is approximately $0.1-5 \%$ and the difference is $3-12 \%$ for $\xi=0$. Thus, the effect of number of realizations and the determination of independent events have greater influence on the results of shape parameter $\xi=0$. According to present results, more than 20 extremes should be used for the classical GEV method to obtain reliable results. While basic wind velocities of GPD with $\xi=0$ approximate the standard basic wind velocity of Hungary $(23.6 \mathrm{~m} / \mathrm{s})$, wind velocities of GPD with $\xi<0$ are also substantially lower than the standard value. 
However, the effect of parameter estimation uncertainty in extreme wind speeds on the assessed reliability index should be investigated later to see its influence on the final result. If this impact is considerable, then this uncertainty should be taken into account in the model.

Acknowledgments: The authors would like to thank the Hungarian Meteorological Service (OMSZ) and the Hungarian Telekom Telecommunications Plc. for providing their meteorological data. The research reported in this paper was supported by the Higher Education Excellence Program of the Ministry of Human Capacities (BME FIKP).

\section{References}

Ciampoli, M., Petrini, F. and Augusti G., 2011: Performance-based wind engineering: Towards a general procedure. Structural Safety, 33, 367-378. https://doi.org/10.1016/j.strusafe.2011.07.001

Coles S., 2011: An Introduction to Statistical Modeling of Extreme Values. Springer Series in Statistics. Springer, London, ISBN 9781849968744.

Cook, N.J. and Harris, R.I., 2001: Discussion of application of the generalized pareto distribution to extreme value analysis in wind engineering by J. D. Holmes, W. W. Moriarty. J. Wind Engineer. Industrial Aerodynam. 89, 215-224. https://doi.org/10.1016/S0167-6105(00)00063-5

Cook, N.J., 1985: The Designer's Guide to Wind Loading of Building Structures: N.J. Cook of Building Structures. Building Research Establishment Dept. of the Environment,; London; Boston: Butterworths, - Building Research Establishment report.

Cooley, D., 2016: Dipak K. Dey, Jun Yan,, Extreme value modeling and risk analysis: Methods and applications. Crc press, Boca Raton.https://doi.org/10.1201/b19721

Ducloux, H. and Figueroa, L., 2016: Background information about the wind action model of cenelec en 50341-1 (2012) and associated expected reliability of electrical overhead lines. J. Wind Engineer. Industrial Aerodynam. 157, 104-117. https://doi.org/10.1016/j.jweia.2016.08.006

EN 1990, 2002: Eurocode - Basis of Structural Design

EN 1991-1-4, Eurocode 1, 2010: Actions on structures: part 1-4: general actions - wind actions. Brussels, CEN.

Fisher, R.A. and Tippett, L.H.C., 1928: Limiting forms of the frequency distribution of the largest or smallest member of a sample, Math. Proc. Cambridge Philosoph. Soc. 24, 180-190 https://doi.org/10.1017/S0305004100015681

Gatey, D.A., and Miller, C.A., 2007: An investigation into 50-year return period wind speed differences for Europe. J. Wind Engineer. Industrial Aerodynam. 95., 1040-1052. https://doi.org/10.1016/j.jweia.2007.01.016

Gnedenko, B., 1943: Sur la distribution limite du terme maximum d'une serie aleatoire. Ann. Mathematics, 44, 423-453. (In France) https://doi.org/10.2307/1968974

Holmes, J. and Moriarty, W.W., 2001: Response to discussion by N.J. Cook and R.I. Harris. J. Wind Engineer. Industrial Aerodynam. 89, 225-227. https://doi.org/10.1016/S0167-6105(00)00064-7

Holmes, J.D. and Moriarty, W.W., 1999: Application of the generalized pareto distribution to extreme value analysis in wind engineering. J. Wind Engineer. Industrial Aerodynam. 83, 1-10. https://doi.org/10.1016/S0167-6105(99)00056-2

Kang, S. and Song J., 2017: Parameter and quantile estimation for the generalized pareto distribution in peaks over threshold framework. J. Korean Statistic. Soc. 46, 487-501. https://doi.org/10.1016/j.jkss.2017.02.003

Kwon, D. K., and Kareem, A., 2013: Comparative study of major international wind codes and standards for wind effects on tall buildings. Engineering Structures. 51, 23-35 https://doi.org/10.1016/j.engstruct.2013.01.008

Liu, J.,, Ren, G., Wan, J., Guo, Y., Yu, D. 2016: Variogram time-series analysis of wind speed, Renew. Energy 99, 483-491. https://doi.org/10.1016/j.renene.2016.07.013 
Lungu D., P.H.A.J.M. Gelder, and Trandafir R.., 1996: Comparative study of Eurocode 1, ISO and ASCE procedures for calculating wind loads. International Association for Bridge and Structural Engineering (IABSE) Report. Vol. 74, pp. 345-354, Delft, 05

Palutikof, J. P., Brabson, B., Lister, D., Adcock, S. T., 1999: A review of methods to calculate extreme wind speeds., Meteorol.Appl. 6, 119-132. https://doi.org/10.1017/S1350482799001103

Paulotto, C., Ciampoli, M., Augusti, G., 2004: Some proposals for a first step towards a performancebased wind engineering. Proceedings of the IFED international forum in engineering decision making; First Forum, December, 5-9, Stoos, Switzerland, http://www.ifed.ethz.ch 01.

Petrini, F., and Ciampoli, M., 2012: Performance-based wind design of tall buildings. Struct.Infrastruct. Engineer. 8, 954-966. https://doi.org/10.1080/15732479.2011.574815

Pickands III, J., 1975: Statistical inference using extreme order statistics. Ann. Statistics 3, 119-131. https://doi.org/10.1214/aos/1176343003

Prud'homme, S., Legeron, F., and Langlois, S., 2018: Calculation of wind forces on lattice structures made of round bars by a local approach, Engineering Structures, 156, 548-555. https://doi.org/10.1016/j.engstruct.2017.11.065

Rózsás, Á., and Sýkora, M., 2016: Effect of statistical uncertainties on predicted extreme wind speeds. 7th International Workshop on Reliable Engineering Computing (REC), June 15-17, Ruhr University Bochum, Germany

Tessari, R. K., Kroetz, H. M., Beck, A. T., 2017: Performance-based design of steel towers subject to wind action. Engineering Structures, 143, 549-557, ISSN 0141-0296. https://doi.org/10.1016/j.engstruct.2017.03.053

Thompson, P., Cai, Y., Reeve, D., Stander, J., 2009: Automated threshold selection methods for extreme wave analysis. Coastal Engineering, 56(10), 1013-1021.

https://doi.org/10.1016/j.coastaleng.2009.06.003 
Appendix A.

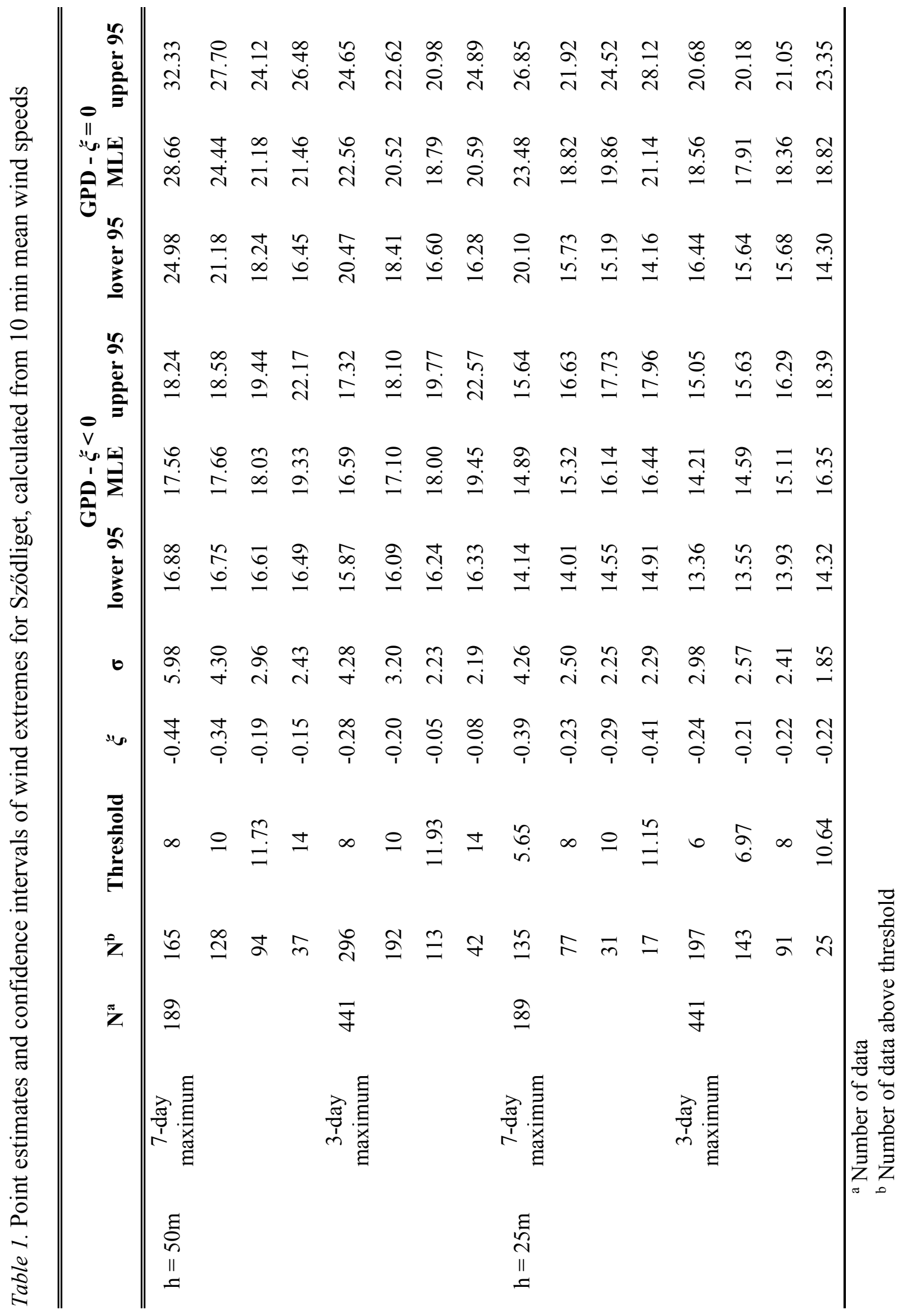



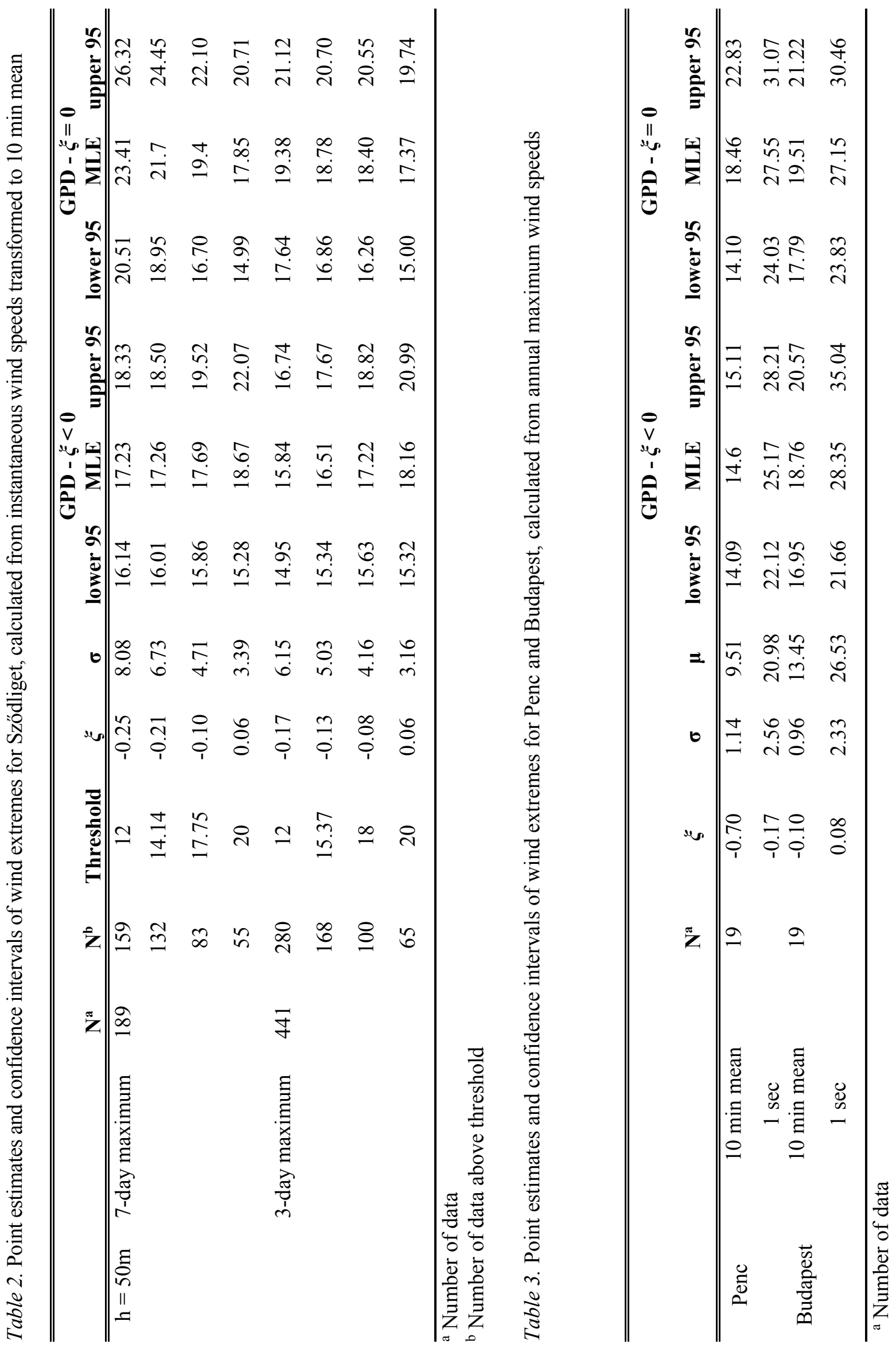


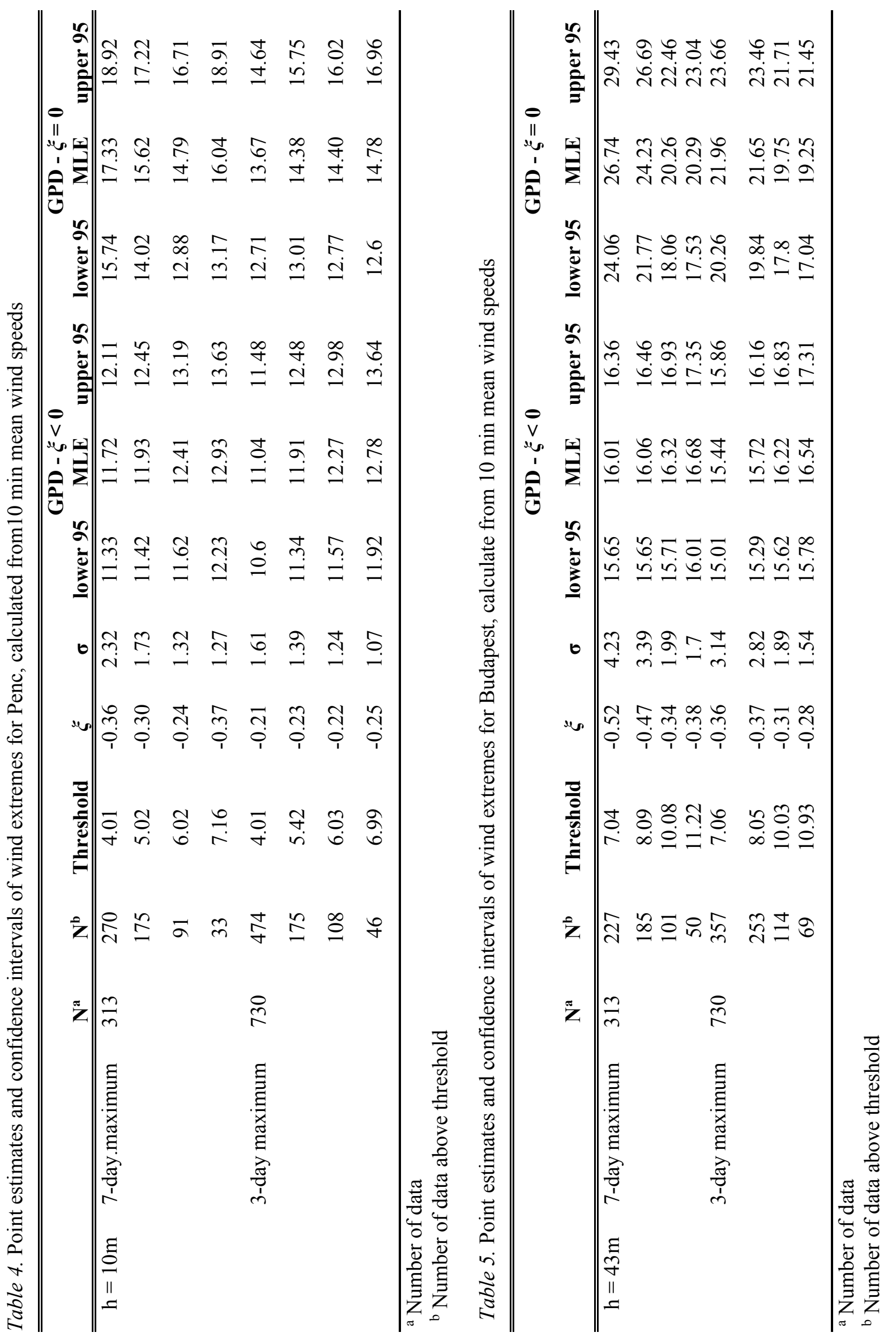

